\title{
BIODIVERSIDADE: FONTE POTENCIAL PARA A DESCOBERTA DE FÁRMACOS
}

Eliezer J. Barreiro ${ }^{\#}$

Departamento de Fármacos, Faculdade de Farmácia, Centro de Ciências da Saúde, Universidade Federal do Rio de Janeiro, CP 68006, 21944-910 Rio de Janeiro - RJ, Brasil

Vanderlan da Silva Bolzani*\#\#

Instituto de Química, Universidade Estadual Paulista, Rua Francisco Degni, s/n, 14800-900, Araraquara - SP, Brasil

Recebido em 16/1/09; aceito em 6/4/09; publicado na web em 9/4/09

\begin{abstract}
BIODIVERSITY: POTENTIAL SOURCE FOR DRUG DISCOVERY. In economic terms, biodiversity transcends the boundaries usually given to conventional industries because it is a valuable source of biological and chemical data of great use to drug discovery. Certainly, the use of natural products has been the single most successful strategy in the discovery of novel medicines, and most of the medical breakthroughs are based on natural products. Half of the top 20 best-selling drugs are natural products, and their total sales amounted to US $\$ 16$ billions shows the importance of natural products, which is evidenced by the new chemical entities (NCE) approved by regulatory authorities around the world in the past decade. Recently, the approval of the alkaloid galanthamine as a medicine to treat Alzheimer's disease shows that natural compounds from plants will continue to reach the market. The huge biological diversity of the Brazilian biomes, by its ability to generate new knowledge and technological innovation can be a fantastic alternative as raw material for drug discovery.
\end{abstract}

Keywords: biodiversity; natural products; drugs; medicinal chemistry.

\section{PREÂMBULO}

Plantas, fungos, insetos, organismos marinhos e bactérias são fontes importantes de substâncias biologicamente ativas, sendo que a maioria dos fármacos em uso clínico ou são de origem natural ou foram desenvolvidos por síntese química planejada a partir de produtos naturais. ${ }^{1}$ Embora existam, nos dias atuais, diversas estratégias e metodologias disponíveis para que se possa sintetizar e descobrir novos fármacos, a química de produtos naturais representa uma destas alternativas de sucesso, historicamente privilegiada. ${ }^{2}$ Muitos metabólitos secundários ou especiais se notabilizaram como matériasprimas valiosas para a produção de inúmeros medicamentos contemporâneos, ${ }^{3,4}$ comprovando que a parceria entre químicos medicinais e químicos de produtos naturais é estratégica para a descoberta de fármacos inovadores. ${ }^{5}$

Segundo estimativas da Convenção da Diversidade Biológica (CDB), o Brasil hospeda entre 15 e $20 \%$ de toda a biodiversidade mundial, sendo considerado o maior do planeta em número de espécies endêmicas. Dados estatísticos indicam ainda que existam 55 mil espécies de plantas, 517 anfíbios (294 endêmicos), 1.622 aves (192 endêmicas), 524 mamíferos (cerca de 130 endêmicos), 468 répteis (172 endêmicos), 3.000 espécies de peixes de água doce e cerca de 15 milhões de insetos, muitos completamente desconhecidos. Com toda essa riqueza biológica, o maior produto de exportação comercial do país ( $c a .40 \%$ ) refere-se a espécies de plantas exóticas, que foram introduzidas como, por exemplo, laranja, soja, cana-de-açúcar e eucalipto. ${ }^{6}$

A biodiversidade do Brasil é considerada uma fonte de substâncias biologicamente ativas e sua preservação é fundamental tanto pelo valor intrínseco dessa imensa riqueza biológica como pelo seu enorme potencial como fonte de novos fármacos, ${ }^{7}$ a qual vem

\footnotetext{
* e-mail: bolzaniv@iq.unesp.br

\# Laboratório de Avaliação e Síntese de Substâncias Bioativas - LASSBio

\# Núcleo de Bioensaios, Biossíntese e Ecofisiologa de Produtos Naturais $-\mathrm{NuBBE}$
}

despertando a cobiça de laboratórios de pesquisa das empresas farmacêuticas localizadas, em sua ampla maioria, ao norte do Equador. Diante desta realidade, várias pesquisas de bioprospecção dos nossos biomas vêm sendo incrementadas objetivando a busca racional de bioprodutos de valor agregado. Dentre as iniciativas desta natureza, merece menção neste artigo o Programa Biota-FAPESP. Criado há 10 anos, foi considerado um dos mais ambiciosos programas brasileiros dedicado ao estudo da biodiversidade e foi concebido originalmente para catalogar todas as espécies remanescentes dos biomas Cerrado e Mata Atlântica do estado de São Paulo. O programa se diversificou e hoje conta com vários projetos de pesquisa dedicados à busca racional de bioprodutos, com destaque para substâncias biologicamente ativas de importância para a indústria farmacêutica. ${ }^{8,9}$ No Brasil, as pesquisas de descoberta de protótipos de fármacos e/ou fitofármacos, além de propiciarem o avanço da pesquisa básica multidisciplinar, podem contribuir também para o desenvolvimento tecnológico nacional, levando em conta que a diversidade micromolecular dos inúmeros biomas brasileiros é ainda muito pouco explorada como uma fonte de substâncias de interesse farmacológico.

Este manuscrito aborda e ilustra a importância da biodiversidade e a natureza interdisciplinar do processo de descoberta de fármacos a partir de produtos naturais considerados líderes de venda no mercado mundial. Ilustra, ainda, um breve panorama da pesquisa no Brasil, exemplificado por duas descobertas realizadas nos laboratórios dos autores que registram a importância da proximidade da Química Medicinal e da Química de Produtos Naturais neste processo fascinante, mas, complexo e de alto risco. ${ }^{5}$

\section{O INÍCIO}

Inúmeras publicações recentes reafirmam a importância dos produtos naturais como fonte de fármacos. ${ }^{10-14}$ Isolada em 1804 pelo farmacêutico alemão Friedrich Wilhelm Adam, a morfina (1, Figura 1) inspirou a descoberta posterior dos derivados 4-fenil-piperidínicos ${ }^{15}$ como uma nova classe de hipnoanalgésicos de emprego mais efetivo e seguro. Esta simplificação molecular ${ }^{16}$ permitiu posteriores otimiza- 
ções e a melhor compreensão do mecanismo de ação analgésica deste alcaloide de importância milenar, originalmente isolado de Papaver somniferum. O alcaloide piperidínico natural serviu de modelo para os químicos medicinais que fizeram sua completa modificação estrutural. Como ilustrado na Figura 1, foram realizadas diversas modificações a partir dos grupos funcionais presentes na estrutura química da morfina. A presença de um álcool alílico na estrutura de $\mathbf{1}$ (anel C, Figura 1) foi fundamental para que, por reações de degradação química sob catalise ácida, se obtivessem produtos estruturalmente mais simples, incluindo a meperidina (2). Este fármaco, descoberto em 1939, é considerado um representante pioneiro da classe, destacando-se pela reduzida propriedade indutora de tolerância quando comparada ao produto natural morfina. Sob a forma de cloridrato ingressou na terapêutica em 1947 como medicamento eficaz para tratar a dor, sendo empregado por via injetável, como a morfina. A vulnerabilidade do éster (em C-4) à ação de esterases plasmáticas inespecíficas leva à formação do ácido $N$-metil-4-fenilpiperidina-4-carboxílico (3) que, por apresentar menor lipofilicidade, não permeia a barreira hematoencefálica. A perda de atividade analgésica deste metabólito plasmático conduziu a novas modificações moleculares produzidas com intuito de prevenir esta via metabólica. Desta forma, o derivado 4-carbonilado (4) foi sintetizado e introduzido na terapêutica como um hipnoanalgésico potente de maior meia-vida na biofase por não se tratar de um substrato específico para as esterases plasmáticas, representando a segunda geração de hipnoanalgésicos oriundos da morfina.

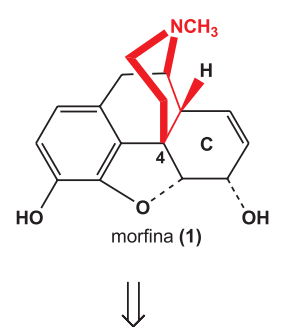<smiles>CCC(=O)C1(c2ccccc2)CCN(C)CC1</smiles>

(4)

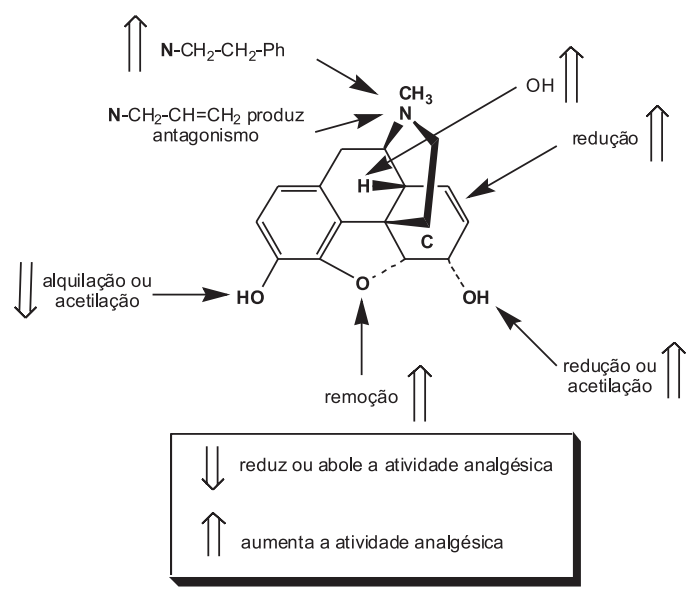

Figura 1. Funções na estrutura da morfina estratégicas para o planejamento de simplificação molecular
Atualmente, a morfina ainda encontra aplicação terapêutica, indicada segundo recomendação da OMS, para tratamento da dor intensa especialmente em pacientes terminais com câncer.

As modificações moleculares mais comuns efetuadas em estruturas de produtos naturais, visando introduzir mudanças nas propriedades relacionadas às fases farmacodinâmica e farmacocinética, compreendem a homologação linear, homologação ramificada e a introdução de grupos vinílogos, fenílogos e benzílogos. ${ }^{17} \mathrm{Um}$ planejamento de simplificação molecular pode ser efetuado para se eliminar centros estereogênicos ou promover a introdução de isósteros funcionais. A anelação molecular assim como a abertura de anéis, a conjugação e introdução de insaturações em cadeias alquílicas ou cicloalquílicas também representam modificações moleculares comumente empregadas. ${ }^{16}$

A simplificação molecular de protótipos derivados de produtos naturais ${ }^{16}$ vem sendo amplamente empregada na descoberta de inúmeros fármacos de classes terapêuticas distintas. Um exemplo clássico trata-se do alcaloide indólico quinina (5), isolado de Cinchona ledgeriana, que por simplificação molecular originou a mefloquina (6). Outras estratégias da química medicinal para o desenho molecular, como o emprego do bioisosterismo, ${ }^{18}$ também vêm sendo aplicadas com sucesso nas modificações estruturais de protótipos oriundos de produtos naturais. A ixabepilona (8, BMS 247550, Ixempra $\left.{ }^{\circledR}\right),{ }^{19}$ macrolido citotóxico semissintético com potente ação anticâncer, foi lançada em 2007 como sendo o primeiro representante de bioisosterismo no mercado farmacêutico, o qual foi descoberto a partir da epotilona B (7) isolada da bactéria Sorangium cellulosum. Embora este produto natural seja bastante potente in vitro, atuando inclusive em linhagens celulares resistentes aos taxanos, apresenta modesta atividade in vivo devido à sua labilidade metabólica que resulta em propriedades farmacocinéticas desfavoráveis. A substituição isostérica na função lactônica da epotilona B pelo grupamento lactâmico produziu a ixabepilona $(\mathbf{8})$ ativa em mais de vinte linhagens de células cancerígenas com $\mathrm{IC}_{50}=1,4-34,5 \mathrm{nM}$, constituindo-se hoje num fármaco de administração parenteral indicado para o tratamento de câncer de mama. ${ }^{19}$<smiles>C=C[C@H]1CN2CCC1[C@H]([C@H](O)c1ccnc3ccc(OC)cc13)C2</smiles><smiles>OC(c1cc(C(F)(F)F)nc2c(C(F)(F)F)cccc12)C1CCCCN1</smiles>

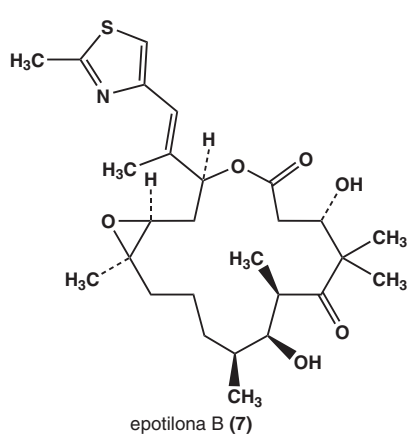

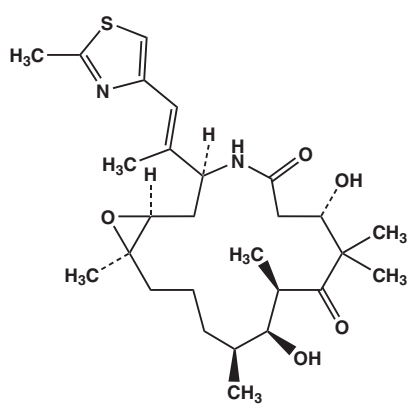

ixamepilona (8)

\section{OUTROS ALCALOIDES IMPORTANTES NO PLANEJAMENTO DE FÁRMACOS}

Inúmeros alcaloides apresentam propriedades no sistema nervoso central, sobretudo os derivados de alcaloides indólicos que ocorrem 
em diversas plantas utilizadas pelos ameríndios e pelos povos africanos como bebidas sagradas nas festas pagãs. ${ }^{7}$ A ibogaína (9), isolada de Tabernanthe iboga (Apocynaceae), é o alcaloide predominante desta espécie cujo extrato hidroalcoólico era largamente empregado por tribos nativas da África, que conheciam suas propriedades alucinógenas e a utilizavam para reduzir a fadiga e a fome. A estrutura da ibogaína foi definitivamente elucidada em 1958 como tendo uma subunidade bicíclica nitrogenada, fundida ao sistema 5-metóxiindólico que contém uma unidade amino etílica similar à serotonina (5-hidroxitriptamina, 10), importante neurorregulador endógeno. Esta similaridade estrutural explica a ação destes derivados nos receptores serotonérgicos centrais. Curiosamente, os extratos de Iboga também apresentavam propriedades afrodisíacas, mais tarde reconhecidas como sendo devido à presença do alcaloide indólico ioimbina (11), tipo corinanteano identificado posteriormente pelas propriedades agonistas de receptores $\alpha 2$.
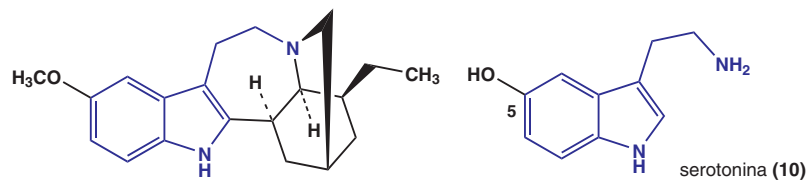

ibogaina (9)

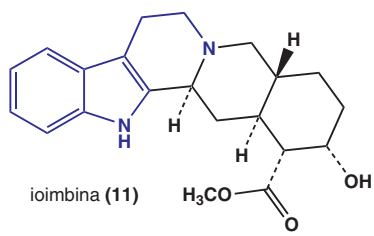

Inúmeros outros alcaloides são representativos da importância desta classe de produtos naturais na descoberta de fármacos, conforme ilustrado na Tabela 1.

Tabela 1. Exemplos de alcaloides protótipos de fármacos

\begin{tabular}{|c|c|c|}
\hline Protótipo natural & Fármaco descoberto & $\begin{array}{l}\text { Indicação } \\
\text { terapêutica }\end{array}$ \\
\hline Quinina (5) & Mefloquina (6) & Antimalárico \\
\hline Pilocarpina (12) & Pilocarpina & Colinesterásico \\
\hline Tubocurarina (13.) & Hexametônio (22) & $\begin{array}{l}\text { Bloqueador } \\
\text { ganglionar }\end{array}$ \\
\hline Papaverina (14) & Sildenafila (23) & Antidisfunção erétil \\
\hline Reserpina (15) & Reserpina & Antiarritímico \\
\hline Mescalina (16) & Anfetamina (24) & Anoréxico \\
\hline Vincristina (17) & Vincristina & Anticâncer \\
\hline Galantamina (18) & Galantamina & AntiAlzheimer \\
\hline Camptotecina (19) & Exatecan (25) & $\begin{array}{l}\text { Inibidor de } \\
\text { topoisomerase-2 }\end{array}$ \\
\hline Huperzina-A (20) & Selagina* (20) & AntiAlzheimer \\
\hline Epibatidina (21) & ABT-418 (26) & $\begin{array}{l}\text { Analgésico } \\
\text { periférico }\end{array}$ \\
\hline
\end{tabular}

* Selagina (20) é sinonímia de huperzina-A (20)

\section{OUTROS PRODUTOS NATURAIS DE RECONHECIDA IMPORTÂNCIA NA PRODUÇÃO DE FÁRMACOS}

Os glicosídeos de Digitalis apesar de apresentarem reduzido índice terapêutico são metabólitos secundários empregados até hoje
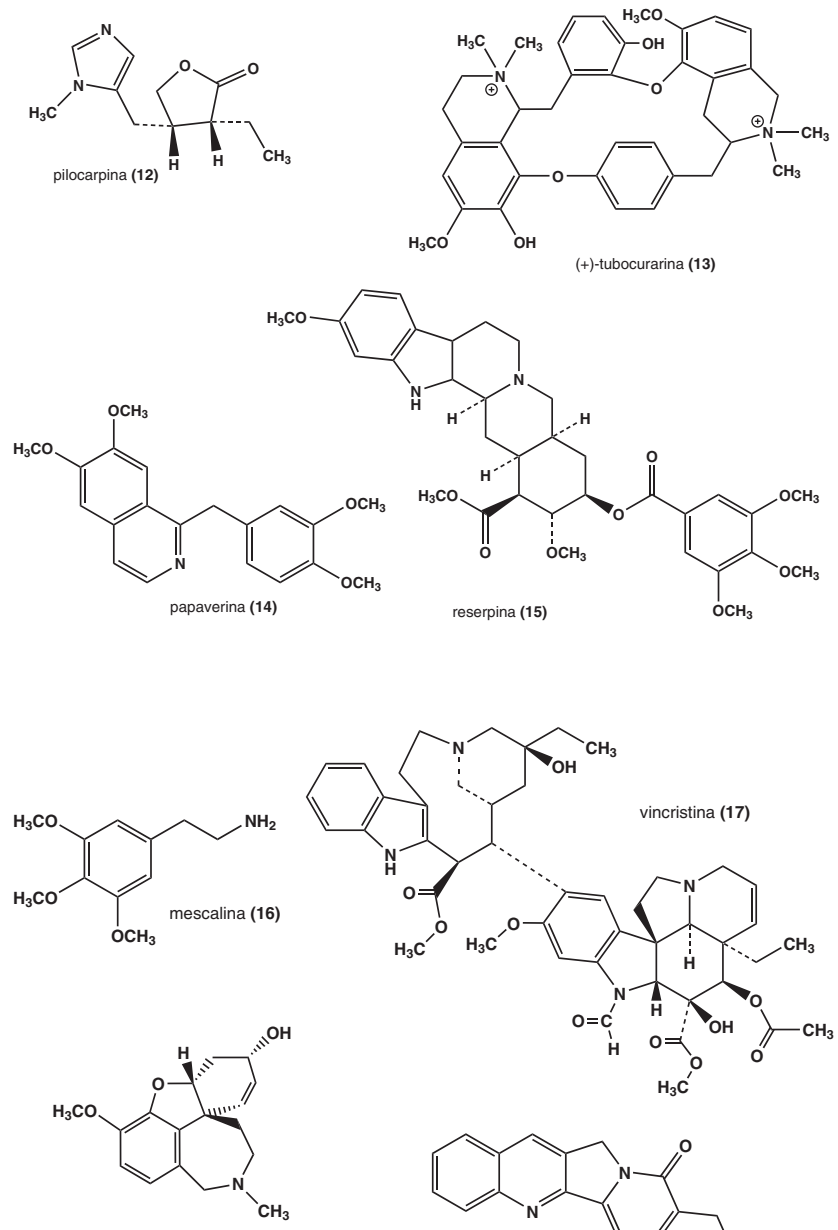

galantamina (18)
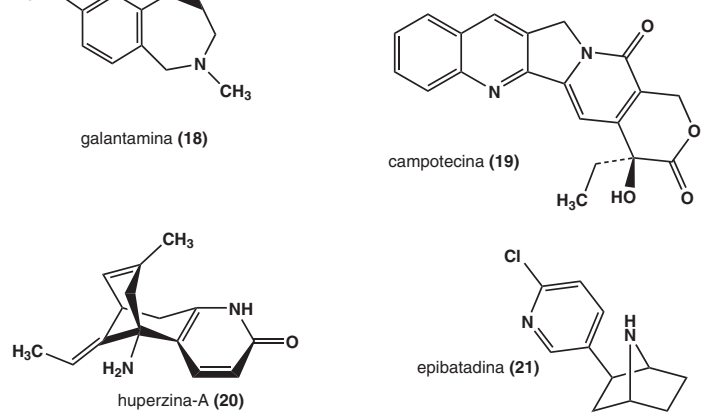

hexametônio (22)<smiles>CC[C@]1(O)C(=O)OCc2c1cc1n(c2=O)Cc2c-1nc1cc(F)c(C)c3c1c2[C@@H](N)CC3</smiles><smiles>CCCc1nn(C)c2c(=O)[nH]c(-c3cc(S(=O)(=O)N4CCN(C)CC4)ccc3OCC)nc12</smiles>
sildenafila (23)<smiles>CC(N)Cc1ccccc1</smiles><smiles>Cc1cc([C@@H]2CCCN2C)on1</smiles>

como cardiotônicos,${ }^{20} \mathrm{em}$ virtude de não ter sido identificado nenhum substituto adequado, com as mesmas propriedades e menor toxicidade. A classe dos cardenolídeos possui um sistema $\gamma$-lactona, enquanto os butenolídeos e homólogos contêm um anel $\delta$-lactônico (ex. digitoxina 27). Estas saponinas esteróidais consideradas "as decanas" dos produtos naturais de origem vegetal são, ainda hoje, reconhecidas pelas suas aplicações milenares na terapêutica humana. 


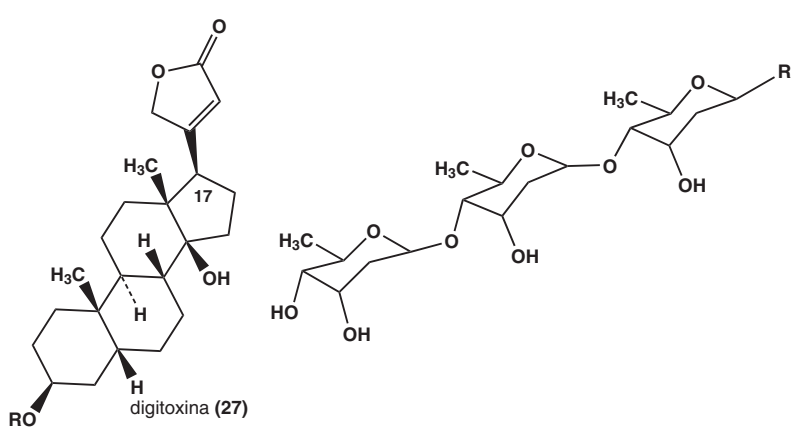

Os diésteres derivados do forbol (28) são substâncias com padrão estrutural peculiar capazes de atuarem como indutores da biossíntese do DNA. Estes diterpenos promovem o crescimento celular através da modulação da enzima proteína-quinase $\mathrm{C}(\mathrm{PKC}) .{ }^{21} \mathrm{Um}$ outro diterpeno importante, de padrão estrutural distinto é a colforsina (29), isolada da planta indiana Coleus forskohlii, que apresenta acentuada atividade inotrópica positiva e vasodilatadora. Estas propriedades se devem, essencialmente, à sua capacidade de estimular diretamente a subunidade catalítica da adenilciclase, resultando em um aumento da concentração intracelular da AMPc (adenosina 3', $5^{\prime}$-monofosfato).

Espécies de uso na medicina tradicional chinesa vêm contribuindo de maneira marcante para a descoberta de novos produtos naturais biologicamente ativos. Um exemplo clássico desta importante contribuição pode ser ilustrado pelo isolamento dos terpenos polioxigenados do extrato da árvore conhecida como ginkgo (Ginkgo biloba). Posteriormente, trabalhos de Nakanishi e colaboradore $^{22}$ permitiram a elucidação de substâncias complexas denominadas de ginkgolídeos, exemplificados pelo ginkgolídeo-B (30) ${ }^{21}$ Estas substâncias naturais apresentam importantes propriedades antitrombóticas e estão sendo caracterizadas como potentes antagonistas dos receptores do fator de ativação plaquetária (PAF) (1- $O$-hexadecil/ $O$-octadecil-2- $(R)$-acetil-sn-glicero-fosforilcolina), um fosfolipídeo endógeno, bioformado em diferentes células, incluindo os eosinófilos, macrófagos, plaquetas, neutrófilos e o endotélio vascular. Os ginkgolídeos atuam como potente mediador celular, capaz de regular uma gama de respostas biológicas, como broncoconstrição e hiperreatividade pulmonar, hipotensão, além de terem sido descritos por Benveniste e colaboradores ${ }^{21}$ como os mais potentes indutores da agregação plaquetária.

Além dos terpenos acima mencionados, outras classes de produtos naturais apresentam importantes propriedades biológicas como o ilustrado pelo gossipol (31). Este derivado fenólico, constituinte do óleo da semente do algodão (Gossypium sp., Malvaceae), foi amplamente empregado na China como contraceptivo masculino. ${ }^{23}$ A propriedade contraceptiva do gossipol foi confirmada em 1980 e neste estudo foi sugerido que o mesmo atue como inibidor reversível da espermatogênese. Este derivado fenólico natural tem características estruturais importantes, constituindo-se num exemplo de atropoisomerismo. ${ }^{24}$ Mesmo que o bis-naftol possua um padrão simétrico, a funcionalização do sistema lhe assegura atividade óptica muito embora não possua carbonos assimétricos. A natureza 2,2-bis-naftalênica 1,1',3,3'-tetra-substituída de sua estrutura, obriga os anéis aromáticos a adotarem conformações ortogonais, especialmente devido à presença dos grupos 3-3'-metílicos criando um elemento de dissimetria molecular, o qual é responsável pela sua atividade óptica. O gossipol possui três formas tautoméricas e é um exemplo de polimorfismo natural que apresenta diferentes estruturas cristalinas, dependentes do solvente de recristalização empregado. Recentemente foi relatado que o gossipol possui potente atividade antiviral, particularmente contra Herpes genital, atribuída à sua capacidade de estimular a biossíntese de interferons.
Inúmeros fármacos tiveram nos produtos naturais um ponto de partida e poderiam ser ressaltados neste texto. Convém ainda mencionar aqui dois exemplos estruturalmente bem mais simples, como o ascaridol (32) e o helmintosporal (33) que foram isolados de espécies vegetais e tiveram suas propriedades anti-helmínticas identificadas.

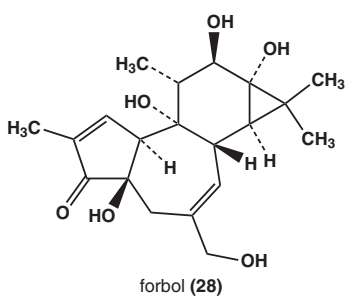

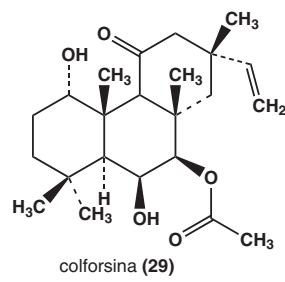

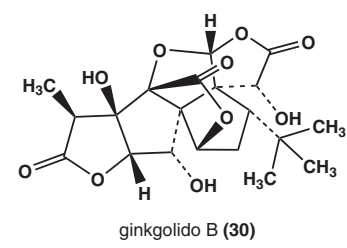<smiles>Cc1cc2c(C(C)C)c(O)c(O)c(C=O)c2c(O)c1-c1c(C)cc2c(C(C)C)c(O)c(O)c(C=O)c2c1O</smiles><smiles>CC(C)C12CCC(C)(CC1)O2</smiles><smiles>CC(C)[C@H]1CC[C@]2(C)[C@H](C)[C@@H]1[C@@H](C=O)[C@H]2C=O</smiles>

Em todos os exemplos apresentados a hidroxila é o grupo funcional predominante nas unidades heterocíclicas e heteroaromáticas, corroborando as constatações apresentadas por Iming e colaboradores numa revisão bastante interessante sobre grupos funcionais preponderantes nos produtos naturais e nos fármacos em uso. ${ }^{25}$

\section{A DIVERSIDADE MOLECULAR DOS PRODUTOS NATURAIS DE MICRO-ORGANISMOS}

Certamente, foram os antibióticos que mais contribuíram para o interesse do setor farmacêutico pelos produtos naturais. Diversos metabólitos secundários com importantes propriedades farmacológicas foram isolados de espécies de bactérias e fungos. A avermectina $\mathrm{B}_{1}$ $(\mathbf{3 4})^{26}$, um macrolídeo isolado de Streptomyces sp., é um agente antihelmíntico potente com amplo espectro de ação sendo recomendado, inclusive, para o combate ao Schistosoma mansoni.

Diversos agentes anticâncer, com diferentes mecanismos de ação, são de origem natural como os derivados antraquinônicos isolados de Streptomyces sp. Dentre estes, destacam-se a daunorubicina (35) e o análogo hidroxilado doxorubicina (36) que são potentes fármacos antineoplásicos. ${ }^{27}$ Estudos sobre o mecanismo de ação antineoplásica da daunorubicina (35) evidenciaram que a unidade naftoquinônica desta substância é o grupamento farmacofórico principal. Este, sofrendo a ação catalítica de uma quinona-oxidase leva à formação de espécies radicalares reativas responsáveis pela formação de ligações covalentes irreversíveis, que promovem a inibição do crescimento celular. A bleomicina $\mathrm{A}_{2}\left(37 \text {, blenoxano }{ }^{\circledR}\right)^{28}$ isolada de Streptomyces werticullus por Umezawa em 1965, mais recentemente, ingressou no arsenal terapêutico. 


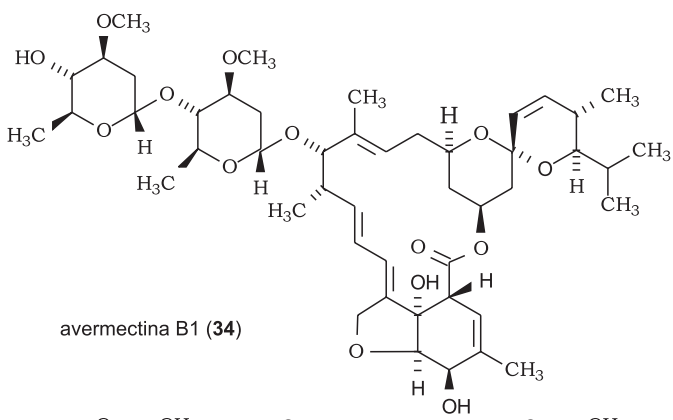<smiles>COc1cccc2c1C(=O)c1c(O)c3c(c(O)c1C2=O)C[C@@](O)(C(C)=O)C[C@H]3OC1CC(C)C(C)C(N)C1</smiles><smiles>COc1cccc2c1C(=O)c1c(O)c3c(c(O)c1C2=O)C[C@@](O)(C(=O)CO)C[C@H]3O[C@H]1CC[C@@H](N)C(C)C1O</smiles><smiles></smiles>

Do fungo Claviceps purpurea foram obtidos os alcalóides do Ergot, conhecidos desde 1875 pelas suas propriedades ocitócicas (diz-se de uma substância que acelera o parto pela intensificação das contrações uterinas) identificadas pelo farmacêutico francês Charles Tarnet. Graças a este perfil farmacológico, a primeira edição da Farmacopéia Americana de 1820 já os incluía como fitofármacos. As propriedades estimulantes das contrações do miométrio foram, algum tempo depois, atribuídas aos derivados estruturalmente relacionados ao ácido lisérgico (38), substância principal isolada de uma fração aquosa obtida a partir do extrato do Ergot, que mesmo após dois séculos de sua descoberta, ainda integra diversas farmacopéias. A partir deste alcaloide foi preparada a metisergida (39), um fármaco semissintético originário da ergotamina (40), principal representante da fração alcaloídica do Ergot.

As modificações estruturais introduzidas na função amídica em C-8 da ergotamina (40), um antagonista $\alpha$-adrenérgico, alteraram de maneira marcante a propriedade farmacológica do alcaloide 40. A metisergida (39) obtida possui propriedade serotoninérgica, responsável pela principal indicação terapêutica no tratamento preventivo da enxaqueca crônica. A presença da unidade $N$-metilindol (a, Figura 2) na metisergida (39) assegurou a proteção metabólica necessária, garantindo uma vida-média adequada na biofase, por prevenir o efeito conjugativo de primeira passagem observado na ergotamina (40).

Os alcaloides do Ergot originaram também o LSD (41, dietilamida do ácido lisérgico), Figura 2, descoberto por Albert Hoffmann nos laboratórios Sandoz em $1943,{ }^{29}$ quando foi modificada a estrutura do ácido lisérgico (38) visando a otimização das suas propriedades ocitócicas. Na verdade, Hoffmann inspirou-se na niquetamida (42) Figura 2, substância ocitócica, com uma subunidade dietilamídica em sua estrutura quando decidiu preparar os derivados análogos de $\mathbf{3 8}$. Durante o planejamento sintético objetivando a introdução da função dietilamida não imaginava que fosse obter o $\operatorname{LSD}(\mathbf{4 1})$, uma das drogas alucinógenas mais potentes. Inúmeros relatos sobre as propriedades desta droga foram feitos, destacando-se o poderoso efeito rebote relacionado a esta estrutura. Uma explicação para o efeito rebote do LSD deve-se à modificação da função amídica que, diferentemente do ácido de origem 38, apresenta propriedade hidrofóbica mais acentuada, favorecendo sua passagem pela barreira hematoencefálica (BHE) de natureza lipofílica. No sistema nervoso central, o LSD atua nos receptores serotoninérgicos devido a sua analogia estrutural com a serotonina, resultando nos efeitos alucinógenos. Por outro lado, amidases centrais podem hidrolisar a função amídica liberando o ácido original que, sendo menos hidrofóbico, não retorna pela BHE e se acumula no SNC favorecendo o aparecimento dos efeitos alucinógenos tempos depois do uso da droga. Embora internalizando a serotonina na sua estrutura, o LSD não é substrato para a monoamina oxidase (MAO), principal enzima envolvida na degradação da serotonina, o que contribui para seu acúmulo e potencialização do efeito rebote.
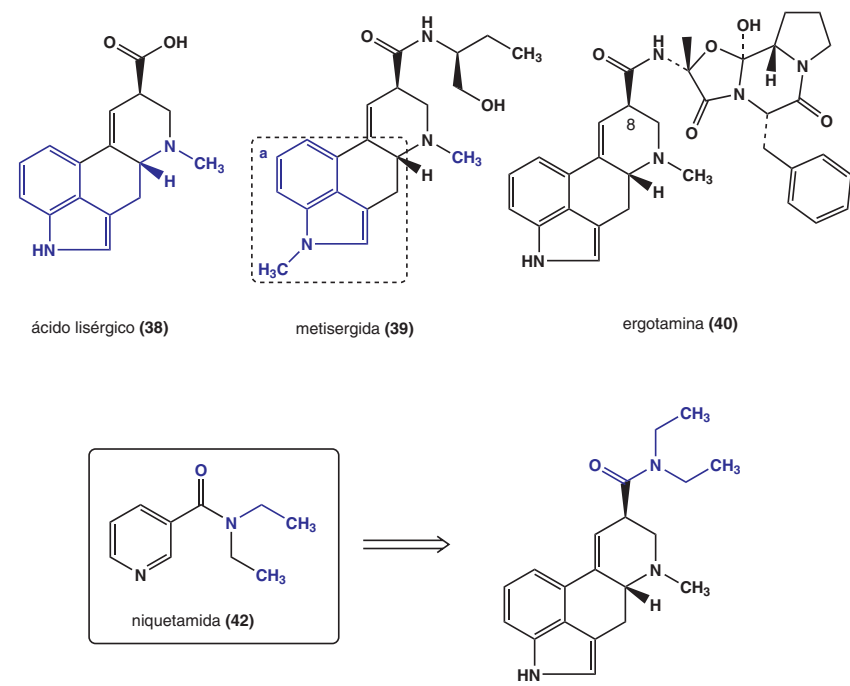

dietil amida do ácido lisérgico (LSD, 41)

Figura 2. Alcaloides do Ergot com propriedades serotoninérgicas

Com a descoberta do LSD, Hoffmann tornou-se um dos principais especialistas em substâncias psicodélicas e, juntamente com Gordon Wasson, notabilizou-se pela pesquisa sobre vários alcaloides psicoativos de origem natural, identificados em várias espécies de cogumelos mexicanos.

\section{PRODUTOS NATURAIS DE ORIGEM MARINHA: UMA FONTE DE NOVOS PROTÓTIPOS DE FÁRMACOS}

Diversos produtos naturais de origem marinha também apresentam importantes propriedades farmacológicas. O sesterpenoide manoalido (43), isolado de uma esponja do Pacífico (Luffariella variablis), caracteriza-se pela presença de um grupamento tipo lactol insaturado em sua estrutura (a, Figura 3), e uma unidade $\gamma$-hidróxibutirolactona, que corresponde à estrutura $\mathbf{b}$ (Figura 3 ) de um anidrido hemirreduzido. Este produto natural é um inibidor irreversível de fosfolipase $\mathrm{A}_{2}\left(\mathrm{PLA}_{2}\right)$ - enzima hidrolítica que libera o ácido araquidônico de fosfolipídios das membranas, principal precursor de mediadores flogísticos, como prostaglandinas e leucotrienos, sendo, 
portanto, um alvo terapêutico para ser usado no tratamento de doenças inflamatórias. O manoalido (43) encontra-se em fase de ensaios clínicos como protótipo anti-inflamatório de uso específico para o tratamento de psoríasis. Este derivado também inibe a mobilização de $\mathrm{Ca}^{+2}$ nas células, sem interferir nos depósitos de cálcio intracelulares, não modifica o nível de inositol trifosfato $\left(\mathrm{IP}_{3}\right)$ indicando que esta atividade depende, principalmente, da presença da subunidade $\gamma$-hidróxi-butenolideo presente em sua estrutura. ${ }^{30}$
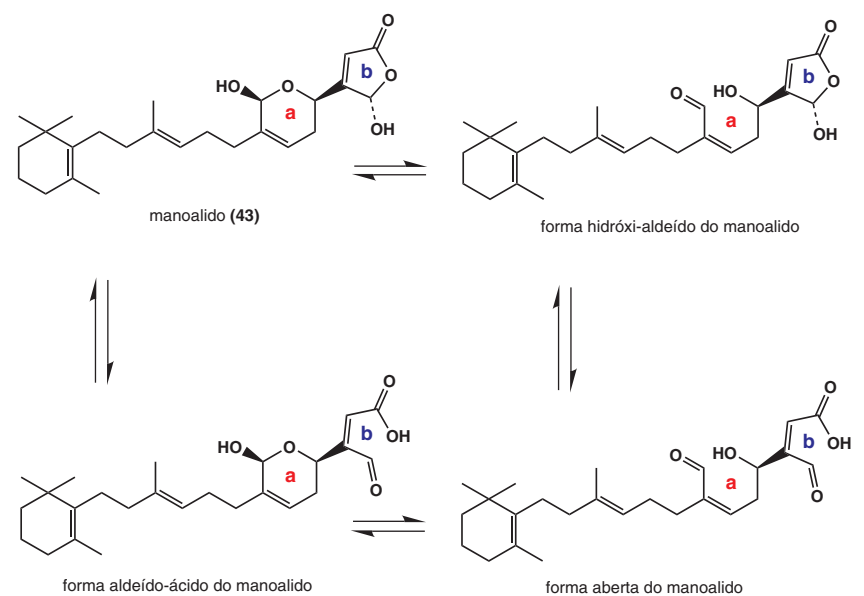

Figura 3. Manoalido (43) e suas formas tautoméricas

Dentro do programa de pesquisa por novos agentes antivirais, especialmente para combate ao Herpes, no laboratório Welcome, a azidovudina (AZT, 44) foi descoberta a partir das propriedades identificadas em nucleosídeos também isolados de algas marinhas. ${ }^{31}$ O AZT foi obtido e ensaiado, mas não se mostrou eficaz contra o Herpes. Com a descoberta do vírus da imunodeficiência adquirida (HIV), responsável pela síndrome da imunodeficiência adquirida (SIDA), esta substância foi reavaliada e caracterizada como um inibidor potente da enzima transcriptase-reversa (TR) viral, tornando-se um dos poucos recursos quimioterápicos contra este tipo de retrovírus. Atualmente, o AZT é considerado um quimioterápico eficaz para o combate ao HIV.

Entre os produtos naturais de origem marinha com propriedades antineoplásicas, encontra-se a briostatina 1 (45), um antileucêmico especialmente importante, devido à potente atividade apresentada por via oral.<smiles></smiles>

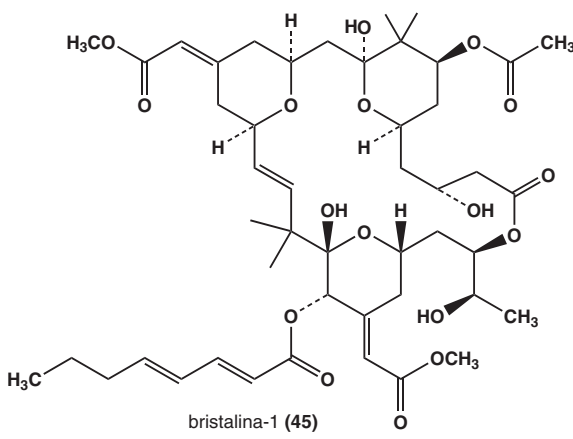

\section{MERCADO BILIONÁRIO DE FÁRMACOS INSPIRADOS NOS PRODUTOS NATURAIS: A DESCOBERTA DO SILDENAFILA}

A cafeína (46), uma trimetilxantina natural descrita como inibidora de fosfodiesterases, é responsável também pelas propriedades de potencializar a vigília e contribuiu para a descoberta recente do sildenafila (23) $\left(\right.$ Viagra $\left.^{\circledR}\right)$. Este novo fármaco desenvolvido pela Pfizer, e lançado no Brasil em 1999, teve sua estrutura planejada a partir do zaprinaste (47, derivado triazolopirimidinônico), um inibidor de fosfodiesterase (PDE) mais seletivo que a trimetilxantina (46) que o inspirou (Figura 4). Os pesquisadores da Pfizer, liderados por Simon Campbell, buscavam inibidores de PDE-3 capazes de serem empregados no tratamento da angina. Entretanto, pesquisando nas substâncias $\mathbf{2 3}$ e $\mathbf{4 7}$ outras propriedades relatadas em estudos de ensaios clínicos referentes à provocação de ereções persistentes, detectaram a isoforma-5 como sendo o alvo do composto desenvolvido, i.e. o citrato de sildenafila que possui o núcleo pirazolo-pirimidinônico, isóstero híbrido do zaprinaste (47) e da cafeína (46)..$^{32}$
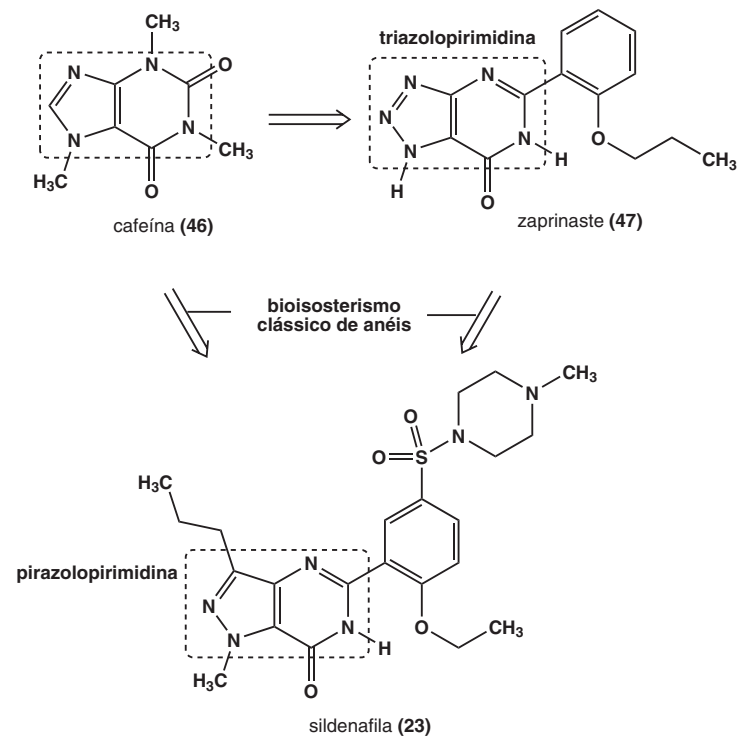

Figura 4. Demonstração esquemática do planejamento do sildenafila (24)

\section{A DESCOBERTA DOS ANTILIPÊMICOS OU ANTICOLESTEROLÊMICOS DA CLASSE DAS ESTATINAS $^{33}$}

A relação patogênica entre o índice de colesterol sanguíneo e o risco de acidentes coronarianos está bem estabelecida, sendo terapeuticamente útil o emprego de inibidores da biossíntese de colesterol para este tratamento. A biossíntese do colesterol (48, Figura 5) é um processo complexo que envolve aproximadamente 26 etapas e pode ser interrompido pela inibição da hidroximetilglutaril Co-A redutase (HMG-CoA). Esta enzima biocatalisa a redução do substrato 49 para ácido mevalônico (50) envolvendo o NADPH (Figura 5). Sua inibição não leva aos efeitos tóxicos decorrentes do acúmulo de seu substrato, em contraste com a inibição da biossíntese do colesterol em estágios mais avançados da cadeia biossintética, onde efeitos nocivos decorrem do acúmulo do intermediário de desmosterol (51).

Durante um programa de ensaios farmacológicos com produtos naturais originários de fungos objetivando selecionar inibidores da biossíntese de esteróides, pesquisadores japoneses liderados por Akira Endo identificaram e isolaram de Penicillum citrinum e Penicillum brevicompactum um inibidor potente de HMG-CoA redutase, identificado como mevastatina, também conhecido como compactina (52), um metabólito secundário de natureza terpênica (ML-236B), que apresenta a subunidade estrutural lactônica (52) estruturalmente similar à HMG-CoA redutase. Estes resultados incentivaram vários estudos nesta área e, em 1987, pesquisadores da Merck Co. identi- 


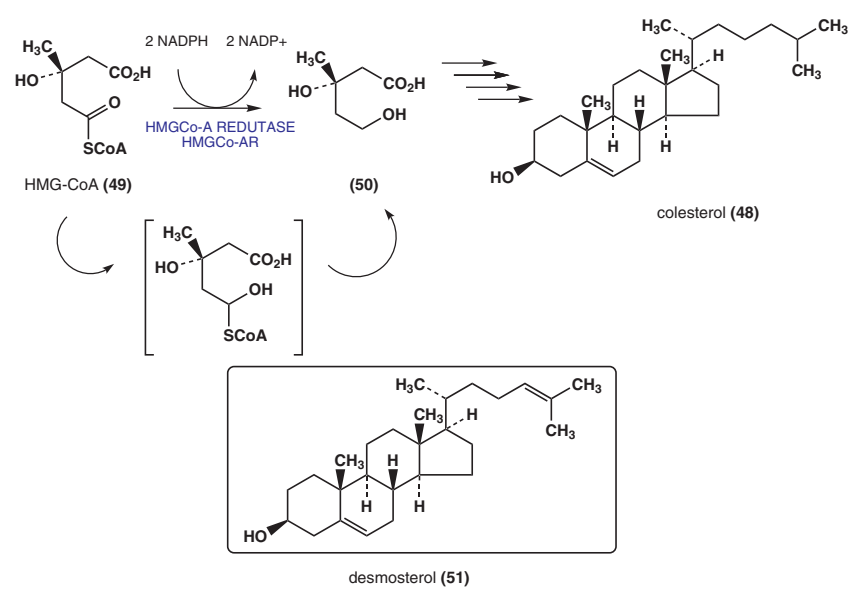

Figura 5. Biossíntese do colesterol envolvendo a 3-hidroxi-3-metil-glutaril-CoA redutase (HMG-CoA redutase ou HMGR), alvo terapêutico das estatinas ${ }^{31}$

ficaram o derivado metilado homólogo da compactina, denominado lovastatina (também conhecido como mevilonina (53), isolado de Aspergillus terreu. Esta substância possui um sistema $\delta$-lactônico que corresponde à forma cíclica do produto de redução da HMG-CoA redutase constituindo-se num autêntico pró-fármaco natural. Em 1987 a lovastatina foi comercializada com o nome de Mevacor ${ }^{\circledR}$. Outros análogos foram descritos pela mesma empresa, como a simvastatina $\left(\mathbf{5 4}\right.$, Zoccor $\left.^{\circledR}\right)$, um derivado 2'-metilado da mevilonina que ingressou no mercado farmacêutico norte-americano em 1992. A simvastatina (54) possui 7 centros esterogênicos, sendo 5 no sistema decalínico e 2 no anel $\delta$-lactônico e a sua forma aberta (hidróxiácido) mimetiza o intermediário tetraédrico envolvido na reação de redução biocatalisada pela HMG-CoA redutase.

Considerando estes fatores estruturais, o anel $\delta$-lactônico foi identificado como o grupamento farmacofórico principal (GF) envolvido no reconhecimento molecular dos inibidores de HMG-CoA redutase, levando à segunda geração de inibidores estruturalmente distintos e simplificados em relação ao protótipo $\mathbf{5 2}$, com cinco centros estereogênicos a menos. O sistema decalínico da nova geração de estatinas foi substituído pela subunidade difenilpiridínica (55) ligada ao GF por um "espaçador" olefínico de configuração $E$, que restringe a flexibilidade conformacional resultando na segunda geração de inibidores seletivos de HMG-CoA redutase.

Posteriormente, Bruce Roth nos laboratórios Parke-Davis desenhou uma nova classe de inibidores da HMG-CoA redutase, contendo, simultaneamente, o sistema cíclico central isostérico 1,2-difenilpirrolo (55a) e o derivado com o GF éster cíclico aberto, a atorvastatina (56) com propriedade terapêutica destacadamente marcante. O planejamento molecular desta substância fundamentou-se no reconhecimento do sistema decalínico da mevilonina $(\mathbf{5 3})^{34}$ como ponto auxofórico hidrofóbico, originando o sistema terfenílico das estatinas de última geração. ${ }^{35,36} \mathrm{~A}$ atorvastatina (56) contendo em sua estrutura molecular o GF 1,2-difenilpirrol foi comercializado em 1991 como Lipitor $^{\circledR} \mathrm{e}$ é o líder em vendas mundiais desde 2003. Este fármaco apresenta como vantagem suplementar aos outros membros da classe disponíveis no mercado, por exemplo, a pravastatina (57), a propriedade de reduzir também a concentração plasmática de lipoproteínas de baixa densidade, em menor dose e mais rapidamente, permitindo um melhor ajuste à posologia. Em 2008, pesquisadores da Pfizer, em Ann Arbor, EUA, ${ }^{36}$ identificaram propriedades antilipêmicas superiores àquelas da atorvastatina $(\mathbf{5 6})$ nos sais sódicos de isósteros pirazólicos (58), com o anel central bis-nitrogenado em substituição isostérica clássica ao sistema pirrólico central da atorvastatina, fármaco com proteção patententária sendo vencida nos EUA, o maior mercado farmacêutico mundial.
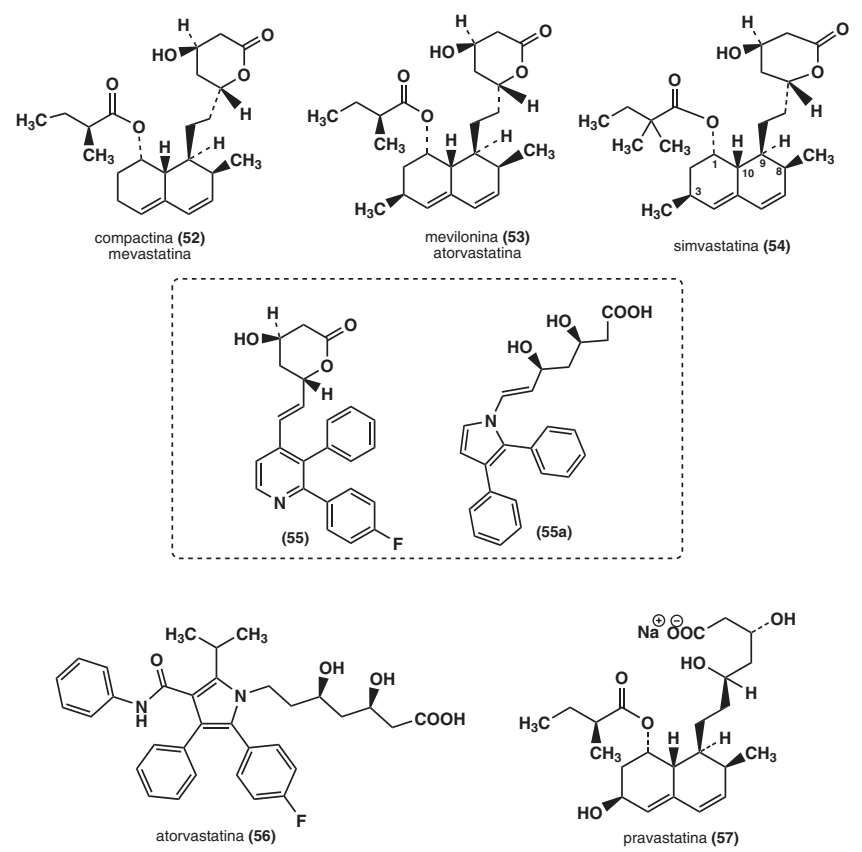

Figura 6. Modelos moleculares que contribuíram para o desenvolvimento da atorvastatina (56)

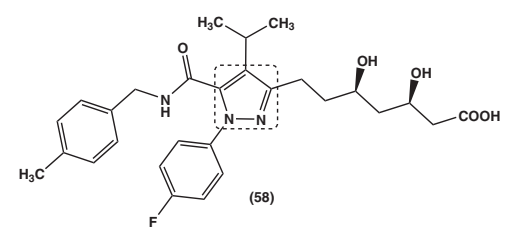

BUSCA RACIONAL DE SUBSTÂNCIAS BIOATIVAS
DA NOSSA BIODIVERSIDADE: UM EXEMPLO DA
COOPERAÇÃO ENTRE A QUÍMICA DE PRODUTOS
NATURAIS E A QUÍMICA MEDICINAL - NUBBE/LASSBIO

As atividades de bioprospecção realizadas pelo NuBBE (Núcleo de Bioensaios, Biossíntese e Ecofisiologia de Produtos Naturais) visam a descoberta de produtos naturais e análogos como antimaláricos, antifúngicos, inibidores de acetilcolinesterase e antitumorais potenciais, a partir de plantas do Cerrado e Mata Atlântica. Desde o início destas atividades de bioprospecção, três espécies de plantas foram selecionadas para pesquisa de desenvolvimento com empresas nacionais do ramo farmacêutico, objetivando a produção de fitomedicamentos da nossa biodiversidade. Dessa pesquisa sistemática com espécies vegetais remanescentes da Mata Atlântica mais de uma centena de micromoléculas e alguns peptídeos cíclicos já foram isolados e, entre estes, o alcaloide piperídinico (-)-espectalina (59), isolado de Senna spectabilis por Bolzani e colaboradores, ${ }^{37}$ mostrou-se de interesse para a inovação farmacêutica, inicialmente devido as suas propriedades analgésicas e citotóxicas.

Durante a apresentação destes resultados em um painel ${ }^{38}$ na Reunião Anual da SBQ, surgiu profícua colaboração com o LASSBio e subsequentemente com o Laboratório de Farmacologia Molecular da UFRJ para reavaliação de $\mathbf{5 9}$ como inibidor de acetilcolinesterase (AChE). O interesse por inibidores da AChE decorre da importância desta classe terapêutica para o tratamento da doença de Alzheimer (DA) que começou em meados da década de 1990, com a utilização da tacrina (THA) (60), um fármaco sintético utilizado apenas no tratamento da DA grave devido aos seus efeitos altamente tóxicos. A descoberta da segunda geração de fármacos inibidores de $\mathrm{AChE}$ 
[donepezil (61), galantamina (62) e rivastigmina (63)] mais eficazes e menos tóxicos testemunham mais uma vez a importância dos produtos naturais motivando, inclusive, a pesquisa de inovação farmacêutica com substâncias oriundas da nossa biodiversidade.

Inspeção estrutural no alcaloide piperidínico 59 permitiu evidenciar alguma similaridade ao nível de sua subunidade cíclica (A) com a acetilcolina, substrato natural da acetilcolinesterase (AChE) ${ }^{39}$ indicando a possibilidade de se obter, através de modificações estruturais adequadas, novos compostos candidatos a inibidores desta enzima, alvo terapêutico importante para o tratamento da doença de Alzheimer (DA) ${ }^{39-41}$ Esta abordagem permitiu a descoberta dos compostos LASSBio-767 (64) e LASSBio-822 (65), ${ }^{39-42}$ que apresentaram potentes propriedades inibidoras da acetilcolinesterase, com elevado padrão de seletividade vis-à-vis a $n$-butirilcolinestarease (BChE), responsável por alguns dos efeitos colaterais dos fármacos disponíveis para o tratamento da DA. ${ }^{43}$ A pesquisa colaborativa entre os 3 laboratórios acadêmicos e a participação da indústria APSEN Farmacêutica foi fundamental para a descoberta de um protótipo da nossa biodiversidade. O derivado semissintético LASSBio-767 (64) foi selecionado para estudo de fase pré-clínica devido à eficácia apresentada na inibição das AChEs cerebrais, apresentando $\mathrm{CI}_{50}$ de 7,3 $\mu \mathrm{M}$. A potência anticolinesterásica deste derivado semissintético foi 20 vezes menor perante a butirilcolinesterase, caracterizando uma seletividade para a inibição da $\mathrm{AChE} .{ }^{39}$ Adicionalmente, os testes in vivo de avaliação dos efeitos de $\mathbf{6 4}$ na memória após tratamento com escopolamina demonstraram ser potente e eficaz na reversão da amnésia colinérgica e menos tóxico que a THA, fármaco sintético em uso. ${ }^{39}$ Todos os ensaios realizados até o momento indicam que 64 apresenta uma clara seletividade central versus periférica, com baixos efeitos colinérgicos no sistema nervoso autônomo, o que não é comum nos anticolinesterásicos disponíveis para tratamento da DA. Os parâmetros farmacocinéticos (de absorção, distribuição, metabolismo e eliminação - ADME) e a duração do efeito de $\mathbf{6 4}$ in vivo estão em estudos avançados, indicando que a pesquisa colaborativa é crucial para a descoberta de fármacos da nossa biodiversidade.
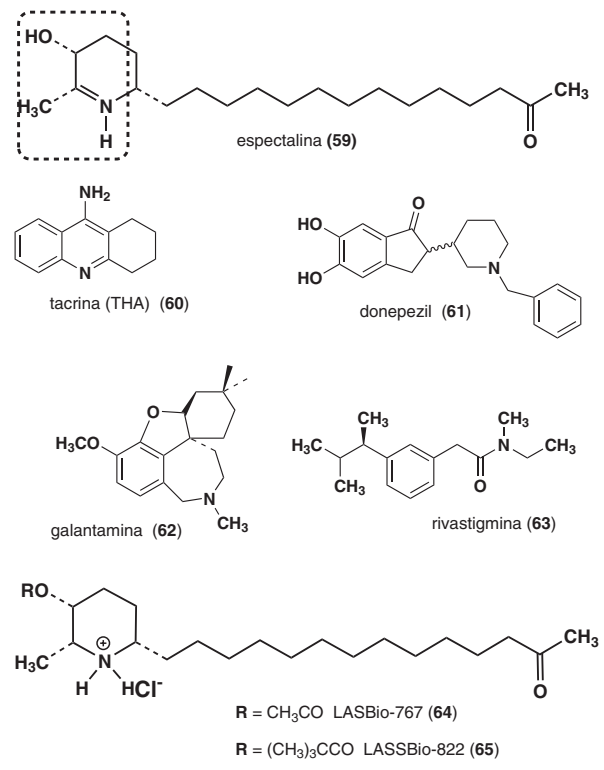

\section{CONCLUSÕES}

Os produtos naturais continuam exercendo seu fascínio na produção de fármacos inovadores como os derivados semissintéticos de artemisinina (66), úteis ao tratamento da malária, o diterpeno paclitaxel (67), ${ }^{44}$ de Taxus brevifolia que é hoje um medicamento utilizado para tratamento de tumores sólidos $\left(\operatorname{Taxol}^{\circledR}\right)$ e a camptotecina (19), alcaloide que inspirou inúmeros derivados que ingressaram no mercado dos fármacos oncológicos. ${ }^{4}$ Substâncias isoladas de organismos marinhos demonstram a importância dos produtos naturais e ilustram sua quimiodiversidade. O peptídeo conotoxina MVIIA (Ziconotide ${ }^{\circledR}$ ), isolado do caracol marinho Conus magus é o primeiro fármaco de origem marinha e foi liberado pelo FDA, em 2004, para o tratamento da dor crônica severa. ${ }^{45}$ Foi de outras fontes naturais, além das vegetais, que Alexander Fleming, na Inglaterra, na primeira metade do século 19 descobriu a penicilina (68), originada de fungos. ${ }^{46} \mathrm{~A}$ classe dos agentes reguladores da hipertensão arterial pertencentes aos inibidores da enzima conversora de angiotensina (ECA), pioneiramente desenvolvida por Ondetti, Cushman e colaboradores nos laboratórios Squibb, ${ }^{47}$ e representada pelo captopril (69), foi planejada a partir dos trabalhos inicialmente realizados por dois eminentes cientistas brasileiros: Maurício Oscar Rocha e Silva e Wilson Beraldo e, posteriormente, por Sérgio Henrique Ferreira, que a partir dos estudos com o veneno da jararaca (Jathropus jararaca) descobriram a bradicinina, construindo as bases para o conhecimento do sistema renina-angiotensina (RAS) de controle da pressão arterial, onde se situa o alvo terapêutico desta classe inovadora de fármacos anti-hipertensivos, a (ECA).
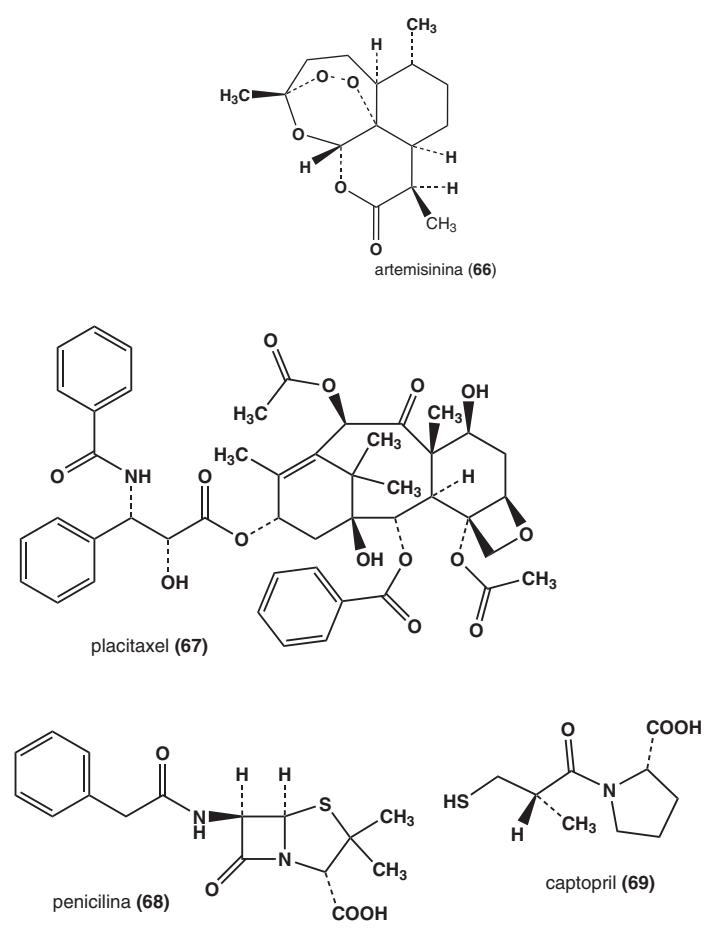

O ácido acetilsalisílico (70, AAS), analgésico centenário e primeiro produto sintético obtido para fins terapêuticos, representando possivelmente o marco zero da Química Medicinal originou-se de um glicosídeo natural (e.g. salicina, 71) identificado como princípio ativo de Salix sp. Esta descoberta ocorrida em 1889 deve-se ao químico Felix Hoffmann que era pesquisador da Bayer.

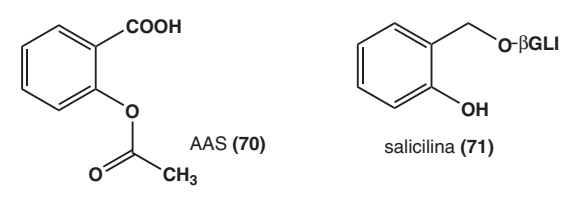


Outras fontes microscópicas presentes na natureza são conhecidas e responsáveis pela descoberta de distintas e importantes classes de antibióticos e das estatinas, dentre esta última destaca-se a atorvastatina, inibidor eficaz da enzima HMG-CoA redutase, envolvida na biossíntese do colesterol, best-seller no mercado farmacêutico moderno que atingiu o faturamento anual, em 2008, de US\$ 13,8 bilhões!

Pelo exposto, inúmeros outros exemplos poderiam ser enunciados neste manuscrito ilustrando a importância da cooperação entre a Química de Produtos Naturais e a Química Medicinal ${ }^{48,49}$ e comprovando uma profunda afinidade entre os fármacos e a diversidade química da natureza. A nossa biodiversidade também é testemunha de vários casos de sucessos de bioprodutos úteis, inclusive de inovações brasileiras representadas pelas recentes descobertas que foram o lançamento, em 2004, do fitofármaco Acheflan, anti-inflamatório de uso tópico, obtido de Cordia verbenacea pelos Laboratórios Aché, e do Helleva , carbonato de lodenafila, substância sintética desenvolvida pela indústria Cristália Produtos Químicos Farmacêuticos Ltda., reafirmando a capacitação efetiva do setor industrial farmacêutico brasileiro na inovação farmacêutica seja de novo fitofármaco ou fármaco sintético, este último inspirado em substâncias naturais, como foram os inibidores de fosfodiesterase 5 (PDE-5) indicados para o tratamento da disfunção erétil, tendo no citrato de sildenafila (46) o protótipo pioneiro.

\section{AGRADECIMENTOS}

Ao Editor deste número especial, Prof. Fernando Galembeck, pelo gentil convite para submetermos esta contribuição. Aos órgãos de fomento FAPESP (Programas Biota e Bioprospecta) e FINEP pelos financiamentos para pesquisa e pelas bolsas de produtividades $(\mathrm{CNPq} \mathrm{e}$ FAPERJ) e aos estudantes e colegas, do LASSBio da UFRJ e NuBBE da UNESP, mencionados nas publicações citadas referentes aos trabalhos de pesquisa realizados nos laboratórios. Os autores agradecem ainda a indústria farmacêutica APSEN Farmacêutica pelo financiamento da pesquisa de fase pré-clinica com o protótipo LASSBIO 767.

\section{REFERÊNCIAS E NOTAS}

1. Baker, D. D.; Chu, M.; Oza, U.; Rajgarhia, V.; Nat. Prod. Rep. 2007, 24, 1225; Harvey, A. L.; Drug Discov. Today 2008, 13, 894; Ganesan, A.; Curr. Op. Chem. Biol. 2008, 12, 306; Newman, D. J.; Cragg, G. M.; J. Nat. Prod. 2007, 70, 461; Koehn F. E.; Carter, G. T.; Nature Rev. Drug Discov. 2005, 4, 206; Butler, M. S.; J. Nat. Prod. 2004, 67, 2141.

2. Mann, J.; Murder, Magic, and Medicine, Oxford University Press: Oxford, 1992, p. 1-16.

3. Cragg, G. M.; Newman, D. J.; J. Nat. Prod. 2004, 67, 232; Newman, D. J.; Cragg, G. M.; J. Nat. Prod. 2004, 67, 1216; Newman, D. J.; Cragg, G. M.; Snader, K. M.; J. Nat. Prod. 2003, 66, 1022.

4. Wall, M. E. Em Chronicles of Drug Discovery; Lednicer, D., ed.; ACS Profissional Reference Book: Washington, 1993, vol. 3, p. 328-348.

5. Lombardino, J. G.; Lowe III, J. A.; Nat. Rev. Drug Discov. 2004, 3, 853.

6. Lewinsonhn, T. M.; Prado, P. I.; Biodiversidade Brasileira - Sintese do Estado Atual do Conhecimento, $1^{\text {a }}$. ed., Ed. Pinsky: São Paulo, 2002, cap. 1, p. 17-25.

7. Barreiro, E. J.; Fraga, C. A. M.; Quim. Nova 1999, 22, 744; Costa, P. R. R.; Quim. Nova 2002, 25, 74.

8. Biodiversity at a Glance, Revista FAPESP Especial 2006, p. 39-41.

9. Para uma visão do setor farmacêutico no atual panorama químicoindustrial, veja: Galembeck, F.; Santos, A. C. M.; Schumacher, H. C.; Rippel, M. M.; Rosseto, R.; Quim. Nova 2007, 30, 1413.

10. Barreiro, E. J.; Manssour, C. A. M.; Química Medicinal: As Bases Moleculares da Ação dos Fármacos, Art Med Editora Ltda: Porto Alegre, 2008, p. 71-135.
11. Oberlies, N. H.; Kroll, D. J.; J. Nat. Prod. 2004 67, 129; Fang W-S.; Liang, X-T.; Mini-Reviews in Medicinal Chemistry 2005, 5, 1; Thomas, C. J.; Rahier, N. J.; Hecht, S. M.; Bioorg. Med. Chem. 2004, 12, 1585; Laekeman, G. M.; Mertens, J.; Totte, J.; Bult, H.; Vlietinck, A. J.; A. G.; J. Nat. Prod. 1983, 46, 161; Laekeman, G. M.; Declerck, F.; Herman, A. G.; Totte, J.; Vlietinck, A. J.; Arch. Int. Pharmacodyn. Ther. 1982, 260, 284.

12. Horowitz, R.; Ullyot, G. E.; Horning, E. C.; Horning, M. G.; Koo, J.; Fish, M. S.; Parker, J. A.; Walker, G.. N.; J. Am. Chem. Soc. 1952, 72, 4330.

13. Kuo, Y. C.; Kuo, P. L.; Hsu,Y. L.; Cho, C. Y.; Lin, C. C.; Life Sci. 2006, 78, 2550; Mal, D.; Senapati, B. K.; Pahari, P.; Synlett 2005, 6, 994; Ishikura, M.; Hino, A.; Katagiri, N.; Heterocycles 2000, 53, 11; Harada, N.; K.; Ozaki, Oda, K.; Nakanishi, N.; Ohashi, M.; Hashiyama, T.; Tsujihara, K.; Chem. Pharm. Bull. 1997, 45, 1156.

14. Srivastava, V.; Negi, A. S.; Kumar, J. K.; Gupta, M. M.; Khanuja S. P. S.; Bioorg. Med. Chem. 2005, 13, 5892.

15. Barreiro, E. J.; Manssour, C. A. M.; Química Medicinal: As Bases Moleculares da Ação dos Fármacos, Art Méd. Editora Ltda: Porto Alegre, 2008, p.161-178.

16. Barreiro, E. J.; Quim. Nova 2002, 25, 1172.

17. Wermuth C. G. Em Molecular Variations in Homologues Series: Vinylogues \& Benzylogues em The Practice of Medicinal Chemistry; Wermuth, C. G.., ed., $3^{\mathrm{a}}$ ed., 2008, p. 275-289.

18. Lima L. M.; Barreiro, E. J.; Curr. Med. Chem. 2005, 12, 23.

19. Hegde, S.; Schimidt, M.; Annu. Rep. Med. Chem. 2008, 43, 473.

20. Fraga, C. A. M.; Barreiro, E. J.; Quim. Nova 1996, 19, 182.

21. Godfroid, J. J.; Braquet, P.; Trend Pharmacol. Sci. 1986, 7, 368.

22. Nakanishi, K.; Wandering, A. Em Natural Products Chemist, Profiles, Pathways, and Dreams - Autobiographies of Eminent Chemists; Seeman, J. I., ed.; American Chemical Society: Washington, 1991.

23. Combs, D. W.; Ann. Rept. Med. Chem. 1997, 32, 191.

24. Santos, A. R.; Pinheiro, A. C.; Sodero, A. C. R.; Cunha, A. S.; Padilha, M. C.; Sousa, P. M.; Fontes, S. P.; Veloso, M. P.; Fraga, C. A. M.; Quim. Nova 2007, 30, 125; Clayden, J.; Tetrahedron 2006, 60, 4335.

25. Imming, P.; Sinning, C.; Meyer, A.; Nat. Rev. Drug Discov. 2006, 5, 821

26. Babu, J. R. Em Biologically Active Natural Products; Curler, H. G., ed.; ACS: Washington, 1988, p. 91-108.

27. da Rocha, A. B.; Lopes, R. M. ; Schwartsmann, G.; Curr. Opin. Pharmacol. 2001, 1, 364; Mukherjee, A. K.; Basu, S.; Sarkar, N.; Ghosh A. C.; Curr. Med. Chem. 2001, 8, 1467.

28. Hecht, S. M.; J. Nat. Prod. 2000, 63, 158.

29. Hoffmann, A.; Agents Actions 1970, 1, 148.

30. Chandra, J. N. N. S.; Ponnappa, K. C.; Sadashiva, C. T.; Priya, B. S.; Nanda, B. L.; Gowda, T. V.; Wishwanath, B. S.; Ranfappa, K. S.; Curr. Med. Chem. 2007, 8, 787.

31. Horwitz , J. P.; Chua, J.; Noel, M.; J. Org. Chem. 1964, 29, 2076; Glinski, R. P.; Khan, M. S.; Kalamas, R. L.; Sporn, M. B.; J. Org. Chem. 1973, 38, 4299.

32. Langtry, H. D.; Markham, A.; Drugs 1999, 57, 967; Maw, G. N.; Ann. Rept. Med. Chem. 1999, 34, 71; Ghofrani, H. A; Osterloh, I. H.; Grimminger, F.; Nat. Rev. Drug Discov. 2006, 5, 689; Campbell, S. F.; Clin. Sci. 2000, 99, 255.

33. Tobert, J. A.; Nat. Rev. Drug Discov. 2003, 2, 517.

34. Viegas Jr, C.; Bolzani, V. da S.; Barreiro, E. J.; Quim. Nova 2006, 29, 326.

35. Jain, M. K.; Ridker, P. M.; Nat. Rev. Drug Discov. 2005, 4, 977; Celik, T.; Iyisoy, A.; Yuksel, U. C.; Isik, E.; Int. J. Card. 2008, 129, 422.

36. Jeffrey, A.; Pfefferkorn, C. C.; Larsen, S. D.; Auerbach, B.; Hutchings, R.; Park, W.; Askew, V.; Dillon, L.; Hanselman, J. C.; Lin, Z.; Lu, G. H.; Robertson, A.; Sekerke, C.; Harris, M. S.; Pavlovsky, A.; Bainbridge, G.; Caspers, N.; Kowala, M.; Tait, B. D.; J. Med. Chem. 2008, 51, 31. 
37. Bolzani, V. S.; Gunatilaka, A. A. L.; Kingston, D. G. I.; Tetrahedron 1995, 51, 5929.

38. Viegas Jr., C.; Bolzani, V. da S.; Furlan, M.; Barreiro, E. J.; Young, M. C. M.; Tomazela, D.; Eberlin, M. N.; J. Nat. Prod. 2004, 67, 908.

39. Viegas Jr., C.; Bolzani V. da S.; Barreiro E. J.; Fraga C. A. M.; MiniReviews in Medicinal Chemistry 2005, 5, 915; Viegas Jr, C.; Moreira, L. L.; Alexandre, M. S.; Fraga, C. A. M.; Barreiro, E. J.; Miranda, A. L. P.; Bolzani, V. da S.; Chem. Pharm. Bull. 2008, 56, 407.

40. John, V. L.; Latimer, H. J.; Tung, S.; Dappen, M. S.; Ann. Rept. Med. Chem. 1997, 32, 11; John, V. L.; Lierberburg, I.; Thorsett, E. D.; Ann. Rept. Med. Chem. 1997, 28, 197.

41. Viegas Jr., C.; Rezende, de A.; Silva, D. H. S.; Castro-Gâmboa, I.; Bolzani, V. da S.; Barreiro, E. J.; Miranda, A. L. P.; Alexandre-Moreira, M. S.; Young, M. C. M.; Quim. Nova 2006, 29, 1279.

42. Viegas Jr., C.; Bolzani, V. da S.; Pimentel, L. S. B.; Castro, N. G.; Cabral, R. F.; Costa, R. S.; Floyd, C.; Rocha, M. S.; Young, M. C. M.; Barreiro, E. J.; Fraga, C. A. M.; Bioorg. Med. Chem. 2005, 13, 4184.
43. Castro, N. G.; Costa, R. S.; Pimentel, L. S. B.; Danuello, A.; Romeiro, N. C.; Viegas Jr, C.; Barreiro, E. J.; Fraga, C. M. A.; Bolzani, V. S.; Rocha, M. S.; Eur. J. Pharmacol. 2008, 580, 339 .

44. Correa, A. G.; Quim. Nova 1995, 18, 460.

45. Sher, E.; Clementi, F.; Neuroscience 1991, 42, 301; Takeda, K.; Nordmann, J. J.; Methods Neurosci. 1992, 8, 202.

46. Chain, E.; Trend. Pharmacol. Sci. 1979, 1, 6; Maurois, A.; La vie de Sir Alexander Fleming, Hachette: Paris, 1959; Chain, E.; Florey, H. W.; Gardner, A. D.; Heatley, N. G.; Jennings, M. A.; Orr-Ewing, J.; Sandres, A. G.; Lancet 1940, 2, 226.

47. Ondetti, M. A.; Cushman, D. W.; Rubin, B. Em Chronicles of Drug Discovery; Bindra, J.; Lednicer, D., eds.; Wiley: New York, 1983, vol. 2, p. 1-31.

48. Lima, L. M.; Quim. Nova 2007, 3, 1456.

49. Bolzani, V. da S.; Viegas Jr, C.; Barreiro, E. J.; Castro, N. G.; Fraga, C. M. A.; Young, M. C. M.; Am. Patent Appl. 0076799, 2008. 